\title{
Globe
}

Revue internationale d'études québécoises

\section{La culture d'entreprise au Québec et la montée en puissance des Québécois francophones. L’exemple de Cascades}

\section{Fernand Cloutier et Jacques Hamel}

Volume 1, numéro 2, 1998

URI : https://id.erudit.org/iderudit/1000513ar

DOI : https://doi.org/10.7202/1000513ar

Aller au sommaire du numéro

\section{Éditeur(s)}

Globe, Revue internationale d'études québécoises

ISSN

1481-5869 (imprimé)

1923-8231 (numérique)

Découvrir la revue

Citer cet article

Cloutier, F. \& Hamel, J. (1998). La culture d'entreprise au Québec et la montée en puissance des Québécois francophones. L'exemple de Cascades. Globe, 1(2), 63-85. https://doi.org/10.7202/1000513ar

\section{Résumé de l'article}

Cet article traite de l'émergence de la culture d'entreprise chez les Québécois francophones. Les auteurs s'intéressent à la culture d'entreprise au sein d'une des filiales du groupe Cascades, qui en est la figure par excellence. La genèse de cette nouvelle forme de concertation en entreprise est d'abord proposée, par un rappel de diverses thèses sur l'économie des francophones au Québec. Ensuite, l'analyse révèle un renversement du rôle de la famille et, plus largement, de la parenté au sein des entreprises. Si jadis les affaires économiques étaient conçues sur le modèle des relations de parenté, aujourd'hui elles sont conçues sur le modèle des relations économiques.
Tous droits réservés @ Globe, Revue internationale d'études québécoises, 1998

The de

Ce document est protégé par la loi sur le droit d'auteur. L’utilisation des services d’Érudit (y compris la reproduction) est assujettie à sa politique d'utilisation que vous pouvez consulter en ligne.

https://apropos.erudit.org/fr/usagers/politique-dutilisation/ 


\title{
La culture d'entreprise au Québec et la montée en puissance des Québécois francophones. L'exemple de Cascades
}

\author{
Fernand Cloutier et Jacques Hamel \\ Université de Montréal
}

La culture d'entreprise, qui avait autrefois le vent en poupe, est désormais en perte de vitesse. Le phénomène se constate au Québec où elle s'est affichée avec éclat durant les années 1980 et où ses porte-parole sont d'ailleurs devenus les vedettes de l'époque. Ces derniers n'avait de cesse d'affirmer que le succès économique de leur entreprise reposait au premier chef sur une culture ouverte à la participation active des employés, gage certain de la concertation. L'ère des affrontements patrons-employés était révolue et les divergences de point de vue en passe de devenir choses du passé. Les parties sociales en présence dans l'entreprise se devaient d'agir en harmonie. Le modèle de l'entente par concertation était prééminent. L'entreprise était, dans cette veine, proposée en exemple à l'État sinon à la société toute entière. Nombre d'hommes d'affaires se sont à cette époque improvisés tribuns et n'hésitaient nullement à traiter certes de problèmes économiques, mais aussi de sujets sociaux de l'heure, se faisant pour l'occasion sociologues ou philosophes.

Sans préméditation aucune, une entreprise et ses propriétaires sont devenus au Québec les figures de proue de la

Femand Cloutier et Jacques Hamel, «La culture d'entreprise au Québec et la montée en puissance des Québécois francophones. L'exemple de Cascades», Globe. Revue intemationale d'études québécoises, vol. 1, no 2, 1998. 
culture d'entreprise. Cascades et les trois frères Lemaire ont défrayé les manchettes, envahi la place publique et acquis la notoriété par leur réussite économique. La relance d'une usine en faillite - par surcroît désuète sur le plan technologique et située en région éloignée - fit la une en raison de la mobilisation que ses propriétaires ont soulevée dans la localité d'abord, puis chez les employés, et l'ingéniosité dont ils ont fait preuve pour la remettre sur pied et la rendre prospère. La doctrine Cascades s'est vite imposée comme culture par excellence de l'entreprise.

La culture d'entreprise peu apparaître au premier abord comme un mot d'ordre ou une mode. Elle est certes cela, mais ne saurait s'expliquer de cette manière en sociologie où elle doit être obligatoirement envisagée comme un fait social, c'est-à-dire le fait de la société et de son histoire, sous leurs divers aspects économiques, politiques, culturels, ethniques, etc. Elle vient rappeler à cet égard que l'économie comporte des dimensions politiques, ethniques et culturelles qui tendent à s'effacer de la production et du marché. C'est ce que nous voulons montrer dans cet article en présentant au lecteur une entreprise du groupe Cascades : Papiers Cascades East-Angus. Cette demière a été choisie pour s'insérer dans une vaste étude sur la place des francophones dans l'économie du Québec.

\section{Cascades et la culture d'entreprise}

Cascades a été mise en lumière par les études d'Omar Aktouf où l'accent est placé sur la culture d'entreprise, envisagée sous deux rubriques différentes. La culture d'entreprise est d'abord associée à une stratégie des dirigeants utilisée dans le but de tirer profit de l'employé. C'est ainsi que le concept «artificiel» de motivation a été remplacé par celui de «corporate culture»... C'est 
désormais à qui saura construire et inculquer à ses troupes la «bonne culture»: "celle de la corporation et de l'intérêt de ses propriétaires et dirigeants, conçue comme étant aussi de l'intérêt des employés, du moins des "bons" parmi eux"'). La culture d'entreprise est également conçue comme une "vision commune» entre les dirigeants et les employés assurant l'essor des entreprises, comme le souffle qui leur est nécessaire pour connaître le succès économique. Cascades en est d'ailleurs lillustration patente. La culture d'entreprise en ce cas est considérée comme le modèle de gestion propice au respect et à la bonne entente dans le sillage de l'esprit rural de naguère et de l'éthique du catholicisme qui a tant marqué le Québec de son sceau. Sa vigueur chez Cascades et d'autres entreprises francophones les place sur un rang concurrentiel à cehui des entreprises canadiennes et américaines. La culture d'entreprise est le fer de lance du leadership et de la bonne gestion nécessaires au succès économique.

Les thèses de l'auteur, pour pertinentes qu'elles soient, doivent être néanmoins nuancées sous bien des égards. Il faut d'abord replacer la culture d'entreprise dans son contexte.

Selon nous, elle ne correspond pas à des valeurs immuables que l'auteur attribue au bon sens, voir au "gros bon sens», pour reprendre son expression. Elle n'est pas une sorte d'application qui donne corps à une gestion aux accents passéistes vue comme une économie capitaliste qui efface toutes divergences entre patrons et employés. En faisant recette, selon notre auteur, la culture d'entreprise apporterait à l'économie des francophones

1 Omar Aktouf, Culture organisationnelle et tâche du gestionnaire de projet, Les cahiers du CETAI, no 87-88, Montréal, octobre 1988, pp. 1011.

2 Omar Aktouf, Renée Bédard et Alain Chanlat, «Management, éthique catholique et esprit du capitalisme : l'exemple québécois", Sociologie du travail, no 1, 1992, pp. 83-99. 
un visage humain sous la forme d'un capitalisme que l'on peut qualifier, pour notre part, d'utopique.

L'émergence de cette culture chez les francophones correspond à l'augmentation significative d'entreprises dont les proprétaires et dirigeants ont la langue française en commun. La propriété de ces firmes était encore récemment majoritairement anglophone, les propriétaires étant anglo-saxons ou américains. Sans basculer en leur faveur, la situation tend à s'améliorer pour les francophones puisqu'ils sont plus nombreux à être propriétaires d'entreprise. Ce demier mot, tout comme celui d'économie, revêtent désormais chez eux une valeur incontestable. Bref, l'entreprise loge à l'enseigne d'une culture, la culture de l'économie dont on doit expliquer l'émergence pour que s'éclaire la culture d'entreprise et, dans cette veine, les récents succès économiques des francophones.

\section{La découverte de l'économie par les francophones}

L'économie des francophones se réduit dans son contexte historique à des entreprises qui ont pour cadre l'agriculture et le village. Elle est dans une large mesure tenue en sujétion par la grande entreprise qui reste l'apanage des anglophones. L'économie des francophones se développe toutefois en parallèle et, pour cette raison, est entravée par la présence et la force des entreprises anglophones. Sans conteste, elle se révèle, en pareilles conditions, une économie dominée par le fait de son rapport avec l'économie dominante anglophone.

Cette domination perdure bien après la Conquête quoique les interprétations de ses «effets» sont l'objet d'âpres débats chez 
les historiens et se colorent de moult nuances. ${ }^{3}$. Il reste que nombreuses études monographiques en donnent un portrait éloquent. Les monographies de petites localités produites dans les années 1930 sous les auspices de l'École de Chicago ${ }^{4}$ lillustrent sur le vif. Everett C. Hughes, étudiant Drummondville, constate sans peine que :

[...] il y a deux sortes d'industries [dans cette localité]. Les premières, propriétés des Canadiens français de l'endroit, sont de petits ateliers manufacturant des produits pour la vente sur le marché local. Les industries de la seconde catégorie... sont la propriété de compagnies de l'extérieur. L'initiative locale a été pour très peu dans leur fondation. Leurs gérants locaux sont anglais et les

3 L'historiographie et la sociographie contemporaines, encore divisées sur le sujet, font écho aux thèses traditionnelles. Selon Fernand Ouellet : «l'effort de dé-dramatisation de la thèse néonationaliste relative à la thèse de la déchéance économique et psychologique de la bourgeoise née avant 1760 ne signifie pourtant pas le déclin radical de cette interprétation. Car elle fut reprise presque intégralement par ceux qui tentent de faire cohabiter d'une façon harmonieuse, en utilisant le concept de classe ethnique, le national et le social.» Fernand Ouellet, «La modernisation de l'historiographie et l'émergence de l'histoire sociale", Recherches sociographiques, vol. XXVI, nos 1-2, 1985, p. 20. Il est donc utile dans la suite de ce texte de rappeler, en s'y appuyant et en les nuançant, l'historiographie et la sociographie traditionnelles qu'on aurait tort de juger périmée. Voir Jean-Pierre Wallot, eL'histoire et le néo-nationalisme des années 1947-1970» dans Guy Rocher [éd.], Continuité et rupture, tome I, Montréal, Presses de l'Université de Montréal, 1984, pp. 111-129.

4 Voir notamment Horace Miner, Saint-Denis : un village québécois, Montréal, Hurtubise HMH, 1985; Everett C. Hughes, Rencontre de deux mondes, Montréal, Boréal Express, 1972. 
produits qu'elles manufacturent sont vendus sur les marché du pays et de l'extérieur.

Les entreprises anglophones font appel à la main-d'œuvre locale, nouvellement issue des campagnes voisines, devenant ainsi un bassin de main-d'œuvre bon marché auquel on n'aura guère recours pour des postes de direction ou de gestion. Les entreprises francophones cuvrent dans leur ombre sans propension à se développer. Elles périclitent in situ sans réellement tirer parti de la présence des grandes entreprises anglophones. Comment expliquer ce phénomène?

Nombre d'études ont déjà été menées sur le sujet. La plus classique est sans conteste $L '$ 'Industriel canadien-français et son milieu de Norman Taylor qui fait référence en la matière. Les entreprises canadiennes-françaises y sont passées au crible d'une comparaison avec les entreprises anglaises, américaines et, dans une moindre mesure, juives. Il en ressort qu'elles ont pour pivot la famille, laquelle freine sinon compromet sérieusement leur développement. Selon l'auteur :

[...] les propriétaires d'entreprises [canadiennesfrançaises] attribuent une trop grande valeur à la famille... les considérations familiales prennent souvent le pas sur les exigences de l'objectivité, à un point tel que les propriétaires en viennent à adopter des comportements non rationnels sur le plan économique contrairement aux chefs d'entreprises anglophones.

5 Everett C. Hughes, pp. 88 et 91.

6 Norman W. Taylor, «L'industriel canadien-français et son milieu», dans René Durocher et Paul-André Linteau [éd.], Le «retard» du 
L'auteur reconnaît pourtant que la famille a son importance dans les entreprises anglophones:

[...] le neveu du patron est d'habitude plus favorisé qu'un autre employé [...] les sentiments affectent de quelque façon les rapports économiques. L'objectivité, néanmoins, est une règle presque impérative pour l'homme d'affaires anglophone.'

Chez lui, les valeurs familiales sont en effet canalisées vers le succès économique de son entreprise. Elles infléchissent la gestion de l'entreprise dans le but de l'orientier vers la croissance. Le neveu du patron obtient sans doute les faveurs de ce dernier, mais en retour il doit les lui rendre en se montrant un employé modèle et en polarisant son travail sur la prospérité de l'entreprise. La famille, sa valeur en son sein, est donc le fer de lance de sa réussite économique. Elle trouve essentiellement sa place dans la direction de l'entreprise dont le propriétaire est généralement assisté de ses enfants ou de proches parents, ses frères par exemple. Elle a toutefois peu d'influence sur la composition de la main-d'œuvre, ni sur l'organisation proprement dite de l'entreprise.

La famille constitue d'emblée d'autres valeurs dans l'entreprise canadienne-française. Elle est l'expression d'un conservatisme néfaste pour le développement de l'entreprise. Jamais ce développement ne doit mettre en péril la «sécurité de la famille». C'est dans cette mesure qu'«on n'envisage pas sans craintes ni réticences l'expansion d'une entreprise, en raison des

Québec et l'infériorité économique des Canadiens franģais, Montréal, Boréal Express, 1971, p. 74.

7 Ibid., p. 74. 
risques que cela implique». En conséquence, les ressources qu'on pourrait éventuellement destiner à la «croissance des entreprises sont souvent employées à d'autres fins - achat de biens immobiliers, achat de valeurs de tout repos ou, souvent, dépenses en vue d'accroître le bien-être de la famille ${ }^{8}$ \%. L'entreprise s'alimente au capital dont dispose la famille; le financement en dehors de son orbite n'est jamais envisagé. C'est de la famille que provient l'ensemble du personnel administratif de l'entreprise. Or, contrairement à ce qui se passe chez les anglophones, la gestion fait non seulement appel au propriétaire assisté de son épouse et de leurs descendants, mais à leurs collatéraux qui s'étendent jusqu'aux lointains cousins. Elle doit en outre obéir à des principes strictement égalitaires :

[...] l'épouse de lun des deux frères propriétaires de l'entreprise où nous nous trouvions fit observer, en termes très vifs, au trésorier de la compagnie, que la justice exigeait qu'il lui remît la somme nécessaire à l'achat d'un manteau de foumure, puisqu'il l'avait déjà fait pour sa belle-sœur.'

Les valeurs qui animent la famille propriétaire de l'entreprise francophone s'étendent à leurs employés sous la forme du paternalisme. En effet, ces derniers sont traités avec des égards particuliers qui, par ricochet, les dotent d'obligations de même nature. Le recrutement des autres employés tend à s'aligner sur l'arbre buissonnant des rapports de parenté. S'ils ne sont pas liés au propriétaire par des rapports de cette nature, ces autres employés sont au service du patron dans la mesure où ses parents les lui ont expressément recommandés. Le propriétaire de l'entreprise, tout comme d'ailleurs le personnel de direction

8 Ibid., p. 52.

9 Ibid., pp. 52-53. 
sous ses ordres, ont à leur égard des rapports qui, selon Taylor, trahissent le patemalisme.

L'entreprise francophone fait ainsi preuve de conservatisme, la famille et ses valeurs qui en sont le pivot freinent sinon compromettent d'entrée de jeu son développement. Selon Taylor :

Parce que la famille est ainsi au centre des préoccupations des hommes d'affaires canadiens français, il s'ensuit que la dimension de leur entreprise est liée à la dimension et à la composition de la famille, aux aspirations et aux aptitudes des membres de la famille. Si la famille, par exemple, compte peu de garçons, on ne cherchera probablement pas à développer l'entreprise; il suffira que l'entreprise puisse faire vivre les membres de la famille. On n'envisagera le développement de l'entreprise que si l'on peut confier les nouvelles responsabilités à d'autres membres de la famille ou de la parenté immédiate. ${ }^{10}$

La famille, incluant la parenté, est dans cette veine mise en procès par Taylor au nom d'un manque de rationalité économique. En effet, selon lui, la valeur qu'elle prend dans les entreprises francophones freine leur développement. Sur cette base, Taylor ne peut toutefois s'empêcher de constater que «dans le contexte où se situe la plupart des hommes d'affaire canadiens-français il s'agit là d'une valeur rationnelle» ${ }^{11}$. Or, à y regarder de près, la famille n'est pas qu'une valeur car c'est par son truchement que se définit la composition de la maind'œuvre, la division du travail et le déroulement des opérations.

10 Ibid., p. 53. 


\section{Le rôle de la famille dans l'entreprise}

La sociographie contemporaine ${ }^{12}$ de l'économie francophone révèle dans le même sens, qu'à une époque donnée, les rapports de parenté jouent un rôle de premier plan dans la gestion et l'organisation des entreprises. La famille en constitue la pierre d'assise et s'étend aux liens de descendance et d'alliance. Elle ne s'assimile donc pas seulement à des valeurs, mais au cadre qui donne corps à la direction, la gestion et l'organisation de ces entreprises.

Les métiers, nombre d'entre eux tout au moins, sont le fait de «familles». Les secrets de leur maitrise se transmettent de génération en génération. Les lignes d'autorité épousent les branches de l'arbre généalogique en vertu desquelles l'aîné domine le cadet, la descendance a préséance sur l'alliance. Le salaire n'est nullement fixé par la compétence ou la responsabilité, mais par les "responsabilités familiales», c'est-àdire le nombre de personnes qui composent la famille. L'embauche de la main-d'œuvre puise dans le réservoir de la famille élargie. Elle a le pas sur l'achat de machines et de dispositifs techniques dont le nombre croissant viendrait diminuer l'importance de sa présence. Ces entreprises ont tendance à acquérir de la machinerie d'occasion, achetée à bas prix, et dont la remise en état de fonctionnement tient occupée, lors d'une baisse d'activité, une partie de la main-d'œuvre régulière. L'innovation technique se traduit dans la modification

11 Ibid., p. 299.

12 Voir Jean Mercier, Les Québecois, entre l'État et l'entreprise, Montréal, L'Hexagone, 1988; Jean-Pierre Dupuis [éd.], Le Modèle québécois de développement économique, Montréal, Presses interuniversitaires, 1995. 
astucieuse de machines désuètes, que l'on rend performantes à coups d'essais et d'erreurs. L'amélioration des savoirs techniques est souvent reliée à un espionnage industriel qui n'ose pas s'affirmer cormme tel. Informés par des proches parents à leur service, des employés s'immiscent dans des entreprises anglophones pour en connaitre les modes d'organisation et pour littéralement pirater les plans des machines et dispositifs techniques qu'ils tentent, à leur retour, de reconstituer avec des moyens de fortune.

Les rapports de parenté constituent de la sorte le pivot autour duquel l'organisation et la gestion des entreprises se développent à une époque qui va du début du siècle jusque vers le milieu des années 1930. En d'autres termes, ils leur donnent forme et c'est sous leur égide que ces entreprises trouvent place dans le contexte de la domination qu'exercent sur elles les entreprises anglophones.

Sur cette base, l'hypothèse développée par l'anthropologue Maurice Godelier et selon laquelle les rapports de parenté "fonctionnent comme rapports sociaux de production»" démontre sa pertinence. Sur sa lancée, la parenté est considérée comme l'armature de l'économie. À notre sens, cette hypothèse conduit à l'explication sociologique de l'histoire des entreprises francophones.

L'insertion de plus en plus poussée de ces dernières dans le giron des entreprises concurrentielles anglophones vient, dès la seconde moitié des années 1930, considérablement diluer la force de ces rapports de production. Elle fait éclater la forme de l'organisation et de la gestion que moulent les rapports de parenté. Les archives de ces entreprises, de même que celles des associations patronales de l'époque, révèlent le désarroi que génère cet éclatement et qui les contraint à se serrer les coudes

13 Maurice Godelier, L'Idéel et le matérieh Paris, Fayard, 1984. 
pour s'armer face à une concurrence devenue incontournable. La «famille» est invoquée à cet égard. Elle ne désigne toutefois plus des rapports de parenté. On passe alors des rapports articulés autour de la famille à ceux de l'ethnicité. Si le jeu de la descendance et de l'alliance y trouve encore sa part, la famille demeure toutefois source de «rapports personnels» suivant l'expression de Jean-Charles Falardeau, c'est-à-dire, des «relations sociales où le sentiment envers les siens joue un rôle important.) ${ }^{14}$

La propriété des entreprises francophones et, sous bien des aspects, la direction, sont encore une affaire de famille. Le ou les patrons adoptent une attitude paternaliste à l'égard de leurs employés en invoquant souvent dans leur communication avec eux l'image du bon "père de famille». Le salaire et les conditions de travail se négocient en l'absence de tierce partie, par rapport direct entre employés et patrons, et ceux-ci le conçoivent comme "personneb. Si la compétence peut être considérée, elle n'efface pas les responsabilités «familiales» quand il s'agit de fixer le salaire qui, en conséquence, varie d'un employé à l'autre. La présence de contremaîtres, d'employés nommés à ce titre, se manifeste sans pour autant empêcher quiconque de franchir la clôture et de s'adresser directement aux patrons. Les «rapports personnels» priment à tous égards sous le toit des entreprises francophones.

Ils deviennent vite le fer de lance du nationalisme économique dont témoignent les premières concertations d'entrepreneurs canadiens-français, parfois sous le couvert de

14 Jean-Charles Falardeau, "L'évolution de nos structures sociales》 dans Marcel Rioux et Yves Martin [éd.], La Société canadiennefrançaise, Montréal, Hurtubise HMH, 1971, p. 125. 
sociétés secrètes ${ }^{15}$, tant l'économie de marché à laquelle elles conduisent doit se promouvoir de façon occulte.

L'État québécois est appelé en renfort. Pour que les entreprises francophones familiales puissent se muer en "grandes affaires", il doit leur apporter son concours. La gestion et l'organisation en leur sein se forment désormais par des «rapports personnels» qui, selon Falardeau, se démarquent nettement des rapports de production anonymes des grandes entreprises anglophones. Selon lui :

[...] habitué à des relations sociales d'un caractère personnel où le sentiment [envers les siens] jouait un rôle important, [le Canadiens français] s'est senti dépaysé dans l'univers bureaucratique et hiérarchisé, où la plupart des contremaitres et directeurs anglais et protestants étaient surtout préoccupés de rendement technique... ${ }^{16}$

La Révolution tranquille entraîne ainsi l'État québécois à devenir un levier économique de choix. Les entreprises familiales en péril quémandent son aide et nombre d'entreprises familiales deviennent propriétés d'État sous l'égide de la Société générale de financement, par exemple. Elles s'ouvrent dès lors à une forte capitalisation, aux techniques de pointe, à la gestion technocratique et à l'implantation de syndicats. Devenues des entreprises concurrentielles, elles sont cédées à des intérêts économiques privés qui ne sont autres que les fonctionnaires de la SGF en passe de devenir les propriétaires d'entreprises qualifiés de garde montante. En parallèle, l'État québécois octroie son aide par la voie de programmes de modernisation

15 Georges-Raymond Laliberté, Une société secrìte : l'ordre de Jacques Cartier, Montréal, Hurtubise HMH, 1983, pp. 28 et suiv.; Yves Bélanger et Pierre Fournier, L'Entreprise québécoise, Montréal, Hurtubise HMH, 1987, pp. 89 et suiv.

16 Jean-Charles Falardeau, op. cit., p. 125. 
des petites et moyennes entreprises qui sont le lot des francophones.

\section{Cascades East-Angus}

Le développement des entreprises Cascades s'inscrit dans ce sillage. Le chef-lieu Cascades Kingsey-Falls est à l'origine une petite entreprise en faillite, rachetée à bas prix avec le concours de la Caisse populaire locale et le soutien de programmes gouvemementaux. Sa relance fait appel à la mobilisation de la population locale. Les nouveaux propriétaires inaugurent une gestion participative bientôt citée en exemple. Nombre d'études seront tirées de cette entreprise, au premier rang desquelles viennent celles d'Omar Aktouf pour qui cette forme de gestion donne l'exemple d'un modèle économique propre aux francophones.

Cascades East-Angus en illustre une autre figure. L'histoire de cette entreprise s'enracine dans l'économie anglophone. En effet, elle prend son essor d'une usine de pâte à papier avec la naissance, en 1907, de la Brompton Pulp and Paper qui devient, en 1931, la St-Lawrence Corporation. Elle passe ensuite aux mains de la Dominion Tar and Chemical Corporation en 1961. L'entreprise est l'image parfaite de l'économie québécoise d'alors. La direction et les postes qualifiés sont l'apanage d'anglophones alors que les francophones constituent la main-d'œuvre de l'usine. Les rapports de parenté y ont une telle incidence qu'ils passent aisément aux yeux d'un observateur pour des rapports sociaux de production.

L'organisation du travail y trouve sa forme et la direction anglophone sait adroitement en tirer parti, voire profit. Le contremaitre anglophone n'a qu'à jouer de son influence sur le 
père de famille pour obtenir la docilité de ses fils qui travaillent à ses côtés. La ligne d'autorité dans l'usine peut avoir l'aîné de la famille pour intermédiaire. En revanche, la famille fait bloc quant il s'agit de s'opposer à la direction de l'entreprise. L'opposition se double du fait que cette dernière est anglophone et ne se rattache d'aucune façon aux diverses branches de l'arbre généalogique des employés. C'est d'ailleurs dans ses ramifications que le syndicat prend racine :

En 1964, quand je suis rentré ici, si c'était anglais, tu gagnais plus cher, puis si t'étais protestant tu gagnais encore plus cher. Ça ce sont des faits, on a des preuves de ça. En 1964, le syndicat est rentré et ça a changé à partir de là. Il y a eu une convention et là ça été plus égal. ${ }^{17}$

Les luttes menées en son nom témoignent toutefois du fait que la «famille» ne repose plus sur les liens de parenté, mais sur des rapports dont la nature personnelle va s'effacer.

L'histoire de la Domtar à East-Angus est par ailleurs celle d'une entreprise en sursis. En effet, des investissements sont consentis pour sa bonne marche, mais sans égard à son avenir. La pollution qu'elle engendre témoigne par ailleurs de sa désuétude. La menace de fermeture plane sur elle en permanence. Elle est toutefois repoussée en vertu de la bonne foi des parties en présence à laquelle obligeait la situation. Le syndicat signale déjà à cette époque l'immobilisme de la Domtar en regard du développement de l'entreprise.

Sa fermeture est annoncée en 1977, à la suite de grèves répétées qui se soldent par un lock-out de six semaines. La concertation est invoquée et un appel est lancé en ce sens au

17 Les extraits d'entrevue sont tirés des entretiens réalisés dans le cadre de la recherche. 
syndicat. Ce demier accepte des mises à pied en échange d'un projet de relance. L'entreprise se montre favorable à la proposition à condition qu'elle rallie $80 \%$ des employés, pourcentage qui n'est toutefois pas atteint. En dépit de cet échec, elle va de l'avant et sa relance débouche sur des bénéfices appréciables sans les investissements susceptibles de la moderniser et, par conséquent, sans laisser présager son maintien à East-Angus. L'imbroglio perdure et l'absence d'investissements à Domtar devient un enjeu politique au sein de la localité. La construction par Domtar d'une nouvelle usine à Windsor s'accompagne de la mise en vente de l'entreprise à East-Angus. Elle est achetée en 1983 par Cascades. Sa venue ravive dans la localité tous les espoirs d'une reprise.

La gestion participative qui fait le renom des frères Lemaire s'appuie sur la concertation locale qui s'est créée pour relancer l'entreprise. La concertation dans l'entreprise émerge à l'ordre du jour. La gestion participative qui se met en place fait largement appel à l'esprit de famille. Elle tranche nettement sur la gestion de la Domtar qui a fait naitre de vives oppositions entre la direction et les employés, avec, pour conséquence, que la famille sinon son «esprit» n'a plus de droit officiel. Certes la famille, les rapports de parenté, se manifestent dans la composition de la main-d'œuvre, mais ils n'ont guère de part dans l'organisation du travail ainsi qu'on l'a vu précédemment.

Les nouveaux propriétaires de l'entreprise font d'ailleurs le rappel de l'importance des rapports de parenté pour donner l'image de leur gestion et de l'organisation du travail qui en découle. $\mathrm{La}$ famille, entendue en ce sens, demeure l'intermédiaire par lequel se transmettent les métiers, du moins certains d'entre eux. En effet, si jadis elle était la voie royale pour apprendre et exercer un métier, lui donnant ainsi tout son lustre, la famille ne sert désormais de tremplin qu'aux emplois peu qualifiés. Les métiers ne sont plus l'apanage de familles particulières, leur acquisition se fait à l'école qui donne à la 
qualification sa valeur et son titre. La famille perd définitivement son emprise sur l'apprentissage des métiers et leur exercice. Il ne reste d'elle à cet effet que l'image du grand patron qui, à l'instar du père, laisse tomber la veste et retrousse ses manches pour montrer un truc de fabrication à des employés auxquels ne le lie nul rapport de descendance et d'alliance.

La gestion de l'entreprise reflète cette image. Elle a pour véhicule la communication qui se veut directe entre la direction et les employés. Elle semble, pour ces demiers, artificieuse à bien des égards. Elle a trait aux anciens rapports de production, mais ne permet d'aucune manière d'insuffler leur forme à l'organisation. du travail en place. Les commentaires des employés chevronnés sont éloquents à cet effet. Quant ils évoquent la valeur qu'ils attribuent à leur travail, ils ne peuvent s'empêcher de souligner : «je ne prends plus ça à cœur, je prends ça à l'heure».

Les termes utilisés témoignent de la nature instrumentale que revêtent dorénavant le travail et son organisation en dépit de l'image de la famille sur laquelle la direction veut les mouler. La direction trahit elle-même la conception instrumentale qu'elle entretient avec ses employés sous des apparences contraires. Cela atteint son comble quand l'un des propriétaires, confronté aux chefs de file du syndicat local, ne manque pas de leur rappeler que les employés sont, pour lui, des marionnettes attachées à sa main par des fils qu'il peut couper à sa guise.

Le syndicat reste dans ces conditions le défenseur des employés. Il fait entendre sa voix au nom d'une solidarité aux accents de la "famille». L'exemple par excellence se manifeste d'abord dans les leaders d'antan rattachés à des lignées familiales dont l'écho de la réputation résonne encore aujourd'hui. La solidarité ouvrière se tisse plus largement dans les rapports de descendance et d'alliance. Le syndicat vient s'y mouler sans toutefois que son rôle et son organisation épousent leurs règles. 
Il est dans ces conditions le porte-parole des employés dont les doléances et revendications ont pour pierre angulaire le maintien des emplois, l'augmentation des salaires et l'amélioration des conditions de travail. Si, dans le passé, elles réservent une part à des considérations familiales, doublées d'incidences ethniques, les récriminations auxquelles le syndicat donne sa voix en viennent à ne plus en faire de cas. Le salaire est assujetti aux compétences et à la place occupée dans la division du travail, point à la ligne. Les conditions de travail sont revendiquées sous cette même enseigne. Le syndicat devient à cet égard le titulaire de la force de cohésion et du pouvoir des employés.

La gestion participative qu'instaure les dirigeants de Cascades n'est pas sans menace pour lui. En effet, l'entreprise, passée sous leur férule, introduit en parallèle des réseaux d'information, des moyens de communication sans intermédiaire avec la haute direction et des comités qui veillent à ce que les employés soient partie prenante des décisions. Le droit de regard des employés sur le chiffre d'affaires, les niveaux de production et la comptabilité générale est désormais acquis. Il est exercé par les employés actifs dans les nouvelles instances de gestion. Ces demières viennent ainsi empiéter sur le terrain du syndicat sans toutefois lui retirer son droit d'exercice.

Le syndicat défend certes ses prérogatives, mais se voit néanmoins contraint de jouer le jeu sur lequel il n'a plus la main haute. Il épouse, par exemple, la logique comptable en vigueur dans les diverses instances de gestion. Ses dirigeants s'initient aux rudiments de la comptabilité et de la gestion dont la formation en ces matières leur est fournie par les cadres de la CSN. Leur intérêt se toume vers les cours de la Bourse, la valeur des actions de la compagnie et les investissements auxquels se livrent les propriétaires.

Or, pris au jeu, les dirigeants syndicaux en viennent à leur faire grief de ne pas suffisamment moderniser l'entreprise, ni 
installer les équipements de pointe susceptibles d'accroître la production. lls dénoncent avec éclat le partage des bénéfices et les sommes allouées généreusement à l'organisation de fêtes et d'activités sociales et sportives qui détoument les profits de leur valeur productive. Le syndicat, tout au moins ses leaders, semble jouer le rôle des dirigeants de l'entreprise tandis que ces derniers veillent au bon traitement de leurs employés. Le paradoxe s'explique par le fait qu'en dénonçant l'écoulement des profits dans le partage des bénéfices ou leur redistribution au profit d'organisations conviviales, le syndicat entend chasser la direction du terrain qui était jadis son lot. En s'appliquant faire de la logique comptable, s'en faisant même le promoteur, le syndicat cherche à défier la réputation de bon gestionnaire attribuée aux dirigeants et aux propriétaires de l'entreprise.

Sous cet angle, le syndicat se dote de prérogatives économiques qui nuancent, voire compromettent, sa vocation de gardien des revendications des employés, lesquelles ne sont pas d'ordre économique. Chez les employés, le syndicat devient un interlocuteur vers qui on peut se toumer dans le cas où, en parallèle, on ne réussit pas à faire entendre sa voix dans les divers niveaux de gestion placés sous la juridiction de la direction.

L'action du syndicat se teinte de couleurs instrumentales qui, par ricochet, marquent le rapport qu'ont désormais avec lui ses membres. Elle joue le rôle d'une soupape de sécurité : «moi je suis protégé par le syndicat. Ça fait que si je crie des bêtises à mon boss, il ne me fera pas ramper par terre. C'est la seule chose que ça me donne. Que je suis content d'avoir. Mais pour le reste...» 


\section{La construction théorique des résultats}

La culture d'entreprise qui marque d'une pierre blanche les entreprises francophones comme Cascades acquiert l'aspect de la famille élargie aux rapports de parenté. Elle est vue sous cette forme sans que toutefois la descendance et l'alliance en soient le véritable levier. La famille se conçoit comme un modèle propre à la gestion participative qui donne à l'entreprise le lustre de la productivité économique. La gestion sous son modèle est gage du succès de l'entreprise. De la sorte, la culture d'entreprise remodelée sous la gestion participative de Cascades exprime sans conteste un renversement de l'économie des francophones au Québec.

$\mathrm{Si}$, à son époque, pour N. Taylor, l'entreprenariat canadienfrançais est freiné par la famille qui avait des incidences directes dans la propriété et la gestion et modelait les rapports avec les employés -, cette même famille se révèle, à l'instar du cas Cascades, le tremplin du développement de cette économie. Elle serait à ce titre le pivot de sa transformation, laquelle marque le renversement de son incidence dans les entreprises francophones. Ce renversement peut être vu dans les termes de Pierre Bourdieu pour qui, à la suite de Weber, «on passe de sociétés dans lesquelles les affaires économiques sont conçues sur le modèle des relations de parenté à des sociétés où les relations de parenté elles-mêmes sont conçues sur le modèle des relations économiques.) ${ }^{18}$

Dans cette optique, on peut affirmer que si elle forme l'image de la gestion participative en vertu de laquelle l'économie des francophones est vouée au succès, c'est qu'à bien des égards la famille en a été naguère la pierre d'assise. La sociologie de

18 Pierre Bourdieu, Raison pratique. Sur la théorie de l'action, Paris, Seuil, 1994, p. 193. 
l'économie québécoise francophone reprend à son compte l'hypothèse déjà évoquée en anthropologie par Maurice Godelier : «les rapports de parenté peuvent dans certaines conditions fonctionner comme rapports sociaux de production.» Sur sa lancée l'économie francophone ne prend nullement les traits de l'économie des sociétés dites primitives qui sont le terrain d'élection de l'anthropologie. Elle ne suggère pas non plus que l'organisation des entreprises épouse l'arbre buissonnant de la descendance et de l'alliance que forme la famille lorsqu'elle est conçue comme rapports de parenté.

L'analyse du cas Cascades tend à montrer que la famille constitue la forme sociale par excellence en vertu de laquelle l'économie des francophones prend corps. Elle se révèle comme la forme de régulation de sa gestion et de son organisation dans les entreprises. Elle est par ailleurs la cheville ouvrière de son articulation à l'économie anglophone dominante. C'est par son entremise que la position de dominée de l'économie des francophones s'est muée en une position concurrentielle. Que Cascades en soit récemment venue à faire bloc avec Domtar pour créer une entreprise d'envergure dans le secteur du papier carton en est la preuve éloquente.

L'hypothèse des rapports de parenté comme rapport de production n'est pas sans nuancer la conception de l'économie élaborée sur le plan de la théorie. L'économie y est souvent conçue dans les termes d'impératifs de la production et du marché. Cette hypothèse tend à souligner que l'économie revêt également une forme sociale. En d'autres mots, elle y trouve sa niche dans le cadre de rapports sociaux.

Selon Godelier, les rapports économiques :

sont les rapports, quels qu'ils soient, entre les hommes qui assument l'une ou les trois fonctions suivantes : déterminer la forme sociale de l'accès aux 
ressources et au contrôle des conditions de la production; organiser le déroulement des procès de travail et répartir les membres de la société entre ces procès; déterminer la forme sociale de la circulation et de la redistribution des produits du travail individuel ou collectif ${ }^{9}$.

L'étude comparative de différentes sociétés - telles celles des aborigènes australiens, des castes indiennes et de la Grèce antique - révèle que l'économie, envisagée sous divers angles, prend la forme de la parenté, de la religion ou des rapports politiques.

Dans cette perspective, pour être bref, la forme sociale de l'économie repose sur une dimension symbolique essentielle que l'auteur en question nomme la part idéelle des rapports de production que désignent les notions courantes de culture et de représentation ${ }^{20}$. En sa qualité d'anthropologue, Godelier assure que :

[...] font parties de l'économie les représentations de la nature qu'une société exploite, les représentations des outils, leur règle de fabrication et d'usage. Ces représentations existent socialement, elles sont donc communicables. Il faut également inclure les moyens linguistiques qui sont nécessaires pour les exprimer et les transmettre de génération en génération, au sein d'une

19 Maurice Godelier, "Anthropologie économique», L'Anthropologie en France. Situation actuelle et avenir, Paris, Éditions du CNRS, 1979, p. 58.

20 Maurice Godelier, «Remarques sur la notion d'idéel et sur quelques-uns de ses usages possibles", dans Michel Amiot et al., Système et pradoxe. Autour de la pensée d'Yves Barel, Paris, Seuil, 1993, pp. 184-194. 
culture. La pensée, les représentations et le langage sont donc des composantes de l'économie. ${ }^{21}$

Il en va de même pour l'économie des sociétés qui sont le terrain d'élection de la sociologie auquel se rattache le cas Cascades.

La gestion participative fait appel à des représentations comme la famille pour donner image à l'organisation du travail et à la participation au bénéfice qu'on veut injecter dans l'entreprise. Elle donne corps à l'économie dans des formes sociales différenciées révélatrices des rapports sociaux de production dont témoigne la présence de la parenté et de l'alliance, de l'ethnicité ou de la religion. En effet, des liens de sang et d'alliance, ainsi que l'ethnicité, par exemple, existent au sens générique dans toute forme de réunion entre êtres humains vivant en société. Ils viennent au premier plan dans la mesure où les liens privilégiés qu'ils établissent entre eux rendent possibles les représentations qui organisent les fonctions dévolues à l'économie : celles qui, selon Godelier, permettent la production et la reproduction de la société.

Les représentations constituent de la sorte la voie d'entrée pour saisir la forme sociale de l'économie bien que son fait les déborde largement. À cet égard, une démarche méthodologique se fait jour dans la veine de l'anthropologie économique proposée par Maurice Godelier.

Le recours à l'image de la famille pour représenter la gestion participative chez Cascades témoigne d'une économie naguère fondée sur les rapports de parenté. La transformation de ceux-ci en un nationalisme économique se mue en une économie qui prend la forme d'une culture d'entreprise orientée vers la qualité totale où la famille n'a phus sa place.

21 Ibid.; L'idéel et le matériel, Paris, Fayard, 1984, p. 181. 